\title{
A Review of the Impact of Accounting Information System for Effective Internal Control on Firm Performance
}

\author{
Susan Peter Teru ${ }^{1}$ \\ Innocent Idoku ${ }^{1}$ \\ Jane Tinyang Ndeyati ${ }^{1}$
}

\author{
${ }^{1}$ Taraba State University, Jalingo, Nigeria. \\ Correspondence: Susan Peter Teru, Taraba State University, Jalingo, Nigeria, Email: susan4dpt@ gmail.com
}

Received: November 18, $2017 \quad$ Accepted: November 20, $2017 \quad$ Online Published: November 27, 2017

\begin{abstract}
Businesses today operate in a highly competitive and changing global business environment and therefore require information system that provides speedy responses to the complex business issue. The rapid development in information technology (IT) has aided companies to generate and make use accounting information systems (AIS), and the qualitative characteristics of any accounting information system to make it effective can be sustained if there is proper internal control system. When companies and businesses adjust and regulate their computerized technique of internal control machinery according to accounting information system (AIS), there would be assurances of the reliability of financial information processes, the control measures of effectiveness and efficiency of the information reliability will be boasted, effectual and improved operative goals and enhanced performance. Therefore, this study focused and look at the influence of accounting information systems (AIS) for effective internal control on firm's performance and found out that when controls are operated efficiently and effectively, there will be improved performance, better accounting information reliability for better decision making for both the internal and external users.
\end{abstract}

Keywords: Accounting, Firm, Information, Internal Control, Performance, System.

\section{Introduction}

Evolution in information technology (IT) has led to the development of new accounting systems, improved economic models and business dealings through the internet. These advancements have lessened time, cost, and money by aiding increased and improved transactions and communication for business dealings. An information system is used mostly by so many organizations to improve and advance the efficiency of business dealings by computerizing existing operations to improve the performance of operations. The role of accounting information system is very crucial in managing an organization and implementing an internal control system. The ultimate objective of accounting information system (AIS) is to gather and record information and data that is a concern to affairs that can economically impact upon firms and ensures operational efficiency and effectiveness of reliability of financial data and legal compliance, Yang et al. (2012). AIS process information and communicate this useful information to both external and internal stakeholders. 
Business organizations operate in a very competitive and complex atmosphere considered by these varying circumstances and extremely unpredictable economic climate. Recently, business organizations started moving faster and faster front globalization technology, part of this changes is an accounting information system (AIS), any of the changes depend on the information and data, to advance an international accounting information system or to make it more effective. Businesses should gather quality data which will yield a quality information about an enterprise, and the information will be used and be the way to controlling, planning, and in making the rightful decision. Certainly, accounting information system is vital to all business organizations and it is the center of the present global chance curve. Therefore, managers and administrators cannot overlook Information Systems because they play a very important role in contemporary society. (Wilkinson et al., 2000; Shah, et al., 2011; Hassan et al., 2013).

Accounting information system is a computer-based system that ensures a quality of accounting information that increases the control and enhances the cooperation in an organization to deliver information available and accessible to the end users who have similar needs. It assists and helps in support of controlling, planning, and organization analysis of its activities. The core function of accounting information system is to give quantitative worth of the past, current, and upcoming economics events. AIS produces the financial statement namely, cash flow statement, income statement, and the balance sheet, and through its computerized accounting system. Customarily, the system processes the data and transform the data into accounting information during input, processing and output stages that can be used by a variety of both internal and external users.

Thus, the effective and successful integration of AIS will be contingent on how well other factors are proficiently used and put in place to facilitate its operation. Similar views had been echoed by some scholars, Markus \& Pfeffer (1983) and Collier (2015) that the successful application and implementation of accounting information systems needs an appropriate fit among three factors such as," perception of the organization concerning the situation, the accounting system must fit when problems are normally solved, and the accounting system must fit with the culture, i.e. the norms and value system that characterize the organization". Grande et al. (2011) contended that IT is readily available and using them gives no competitive advantage for accomplishing better outcomes. They claimed that many firms have invested in IT but failed in achieving the established performance goals. This, therefore, indicates that AIS can only be beneficial in organizational operations only when appropriate factors are put in the right place and operated harmoniously.

Therefore, AIS can be only efficient when companies can regulate and adjust their computerized systems of internal control mechanism accordingly, which is one of the most vital components of any organization and AIS, then they will be able to ensure the trustworthiness of their financial information processing and improve the control measures of the financial information reliability and effectiveness. Accounting information system helps managers to comprehend their task more evidently and lessen uncertainty before making decisions, Gexin (2013).

\section{Literature Review}

Accounting information system differs widely as it is adopted across the world, in organizations and businesses, or in the other word as said by Kieso et al., (2011), "accounting information are built or designed to be adapted to the conditions and situations that are relevant to the organizations. Accounting information system as a system processes data and transactions to provide users with the information they need to plan, control and operate their businesses, Stair and Renoid (2010). Accounting information systems are observed here according to the views of other authors, Laudon \& Laudon (2012) and Hall (2011) as a system that helps management in planning and controlling processes providing relevant and reliable information for decision making. They 
propose that the function of accounting information system is not only for producing financial reports. Its function goes beyond this traditional perception. Romney and Steinbart (2010) attested that accounting information system should be functioned to include planning and managing business activities. It could also be used as a controlling mechanism such as budgeting. According to Hall (2011), the value of accounting information to the user depends on how reliable is the information, and information is said to be reliable when it has the attribute of relevance, complete, accurate, concise, and at the right time, and for all of it to happen, it must possess certain relevance attribute as accuracy, completeness, summarization, and timeliness as it will be discussed in detailed below as qualities of good accounting system.

O' Brien and Maracus (2010), the relevance of accounting information depends on the quality characteristics of the information required by the user in making valuable decisions and achieving its organizational goals. According to Gelinas et al., (2012) and Azhar (2009), the relevance of accounting information depends on how useful it is for decision making. The same information was also given by Strong et al. (1997), that the information is only relevant if it meets the need of the information consumer.

Accounting information systems are measured as significant organizational mechanisms that are necessary for the effectiveness of decision making by the management and control in organizations Hall (2012). Studies by Markus \& Pfeffer (1983) have shown that" effective implementation of accounting systems requires a fit between three factors. A fit must be attained with the main view in the organization or perception of the situation. Secondly, the accounting system must fit when problems are normally solved, i.e. the technology of the organization. Finally, the accounting system must fit with the culture, i.e. the norms and value system that characterize the organization". Systems will be useful when information provided by them is used effectively in the decision-making process by users Christiansen \& Mouritsen (1994). According to Wilkinson (2000), an accounting information system main function is to give a quantitative value of the past, present, and future economics actions. AIS produces the financial statement namely, income statement, the balance sheet, and cash flow statement through its computerized accounting system. The system normally processes the data and converts them into accounting information during input stage, processing and output stages which can be used by a several of users both the internal and external users.

From the sense of the above contribution of the importance of accounting information system, it can be concluded that accounting information system needs to be useful and suitable for decision making by the users and the information should have a distinctive feature that will meet or even exceeds the expectation of the users.

\section{Objective of the Research}

- To examine if the use of accounting information system (AIS) has an impact in improving the internal control and improves firm performance.

\section{Research Methodology}

The drive of this research is to evaluate the impact accounting information system for effective internal control and firm performance which indicated that a good internal control ensures reliable financial report for decision making and improves firm's performance. The qualitative method of data collection was used for the study with various related previous literature being reviewed, and other secondary data to be able to come up with trustworthy conclusions which are based on the empirical data.

\section{Data Analysis and Interpretation \\ 5.1 Accounting Information System and Data Quality}


Redman (1992), accounting information system (AIS) output depends on the quality of data, garbage in garbage out is the result of poor data quality, and therefore data quality is important to AIS Xu (2003). All data production processes (data collection, data storage, and data utilization) must work properly to achieve high data quality Lee \& Strong (2003). According to Xu (2009), inaccurate and incomplete data may damage the competitiveness of firms. They also found out that that input control and competent employees are important to data quality of accounting information system. Poor information quality may have an adverse effect on decision making Huang et al., (1999). Quality of accounting information can be evaluated by four attributes, Accuracy, timeliness, completeness, and consistency Xu (2003) they examined critical success factors for accounting information quality, they identified and interviewed four groups namely information producers, information custodians, information consumers and information managers. They found and suggested that organizational issue, system, and human issue are very much important to accounting information quality. Rahayu (2012) found the influence of management commitment on data quality and AIS. He found out that management commitment and quality of data together have adequate effect on the accounting information system, although he suggested that contribution of management commitment need to be improved and to management adequacy training and funding of resource development need to be considered by organizations.

Azhar (2016), quality accounting information system has a significant effect on accounting information quality but when the AIS is not built well, it will not be able to produce quality information in accordance with the expectation of the users. He added that through the application of quality information system, the users will be able to obtain quality information at the right time for the right decision. Laudon \& Loudon (2012), accounting information system ensures the quality of information in support of controlling, planning and activity analysis of the organization in accordance with the purpose and function of the accounting information system (Secure et al., 2006; Susanto 2008; Hall (2011). According to Azhar (2009), and Gelinas et al., (2012), information becomes useful only when it has the quality characteristics required by the users in making decision valuable and in achieving the organizational goals.

According to McLeod \& Shell (2007) and Romney \& Steinberg (2012), the criteria of quality information is when the information is suitable for the user, and has a distinctive feature that meet or even exceeds the expectations of the users and that the information should be timely, accurate, complete and relevant, while Kartikahadi et al., (2012), said that the accounting information system should be understandable, comparable, reliability

\subsection{Accounting Information System and Internal Control}

Azhar (2013), management and businesses expect to have meaningful accounting information to enable them to make decisions by having a good internal control running their information systems. According to Hurt (2008), Romney \& Steinbert (2009), the main goal of accounting information system (AIS) is to control the business of every organization, the management/ accountant can accomplish this goal by designing an effective internal control. Organizations will experience fraud without a good internal control on accounting information system. Organizations must have an effective internal control to achieve the mission and performance of the profitability objective and to minimize risk in the business dealings (0'Brien \& Marak,2010).

Toposh (2014) emphasized that the qualitative characteristics of accounting information in an organization are to have an effective internal control. The procedures of internal control are set up to protect assets, ensure reliable accounting reports, promote efficiency and encourage adherence to company policies. The procedures also are essential to achieving some objectives like efficient and orderly conduct of accounting transactions, safeguarding the assets in adherence to management policy, prevention of error and detection of an error, 
prevention of fraud and detection of fraud and ensuring accuracy, completeness, reliability and timely preparation of accounting data. According to Hallandy \& Ghabban (2009), internal control of accounting information system is the integrity of its financial and administrative information system, which equally means if good internal control exists in an organization, management/users can use information with more confidence to maintain their business activities properly which provide efficient AIS, but if the internal control is not effective, management cannot achieve its goal and make good decision.

Yang et al. (2011), for a reliability of financial reporting, a performance of operations, and legal compliance, internal control mechanisms must be built gradually into the enterprise information system. Strong internal control is relevant to organizations because of the vulnerability of fraud and is closely related to information systems. Musa (2010), "Management relates the information of current performance to budgets, forecast, prior periods, or another benchmark to measure the extent to which goals and objectives are being achieved and to identify the unexpected results or unusual conditions that require follow up". The management has line responsibility for designing, implementing and monitoring internal control system for identifying the financial and compliance risk for their operations. Sajady et al. (2008) specified that the application of accounting information system could lead to a better decision making by administrators, more effective internal control, improvement of the quality of financial reports, and enabling financial transaction procedures.

Marshal \& Paul (2015) "Internal controls are processes implemented to provide reasonable assurance that the following control objectives are achieved; Safeguard assets, maintain records in sufficient detail to report company assets accurately and fairly, provide accurate and reliable information, prepare financial report in accordance with established criteria, promote and improve operational efficiency ,encourage adherence to prescribed managerial policies, comply with applicable laws and regulators".

Romney \& Steinbeith (2015), "internal Control is a process, affected by an entity's board of directors, management, and other personnel, designed to provide reasonable assurance regarding the achievement of objectives, three categories like reliability of financial reporting, compliance with applicable laws and regulations and effectiveness and efficiency of operations. Effective internal control systems are essential for successful operation of the business as well as accounting control and administrative control. It helps the Accounting Information Systems division to generate reliable and relevant information". In the AIS environment, the qualities of internal controls adaptation affect operations and management and in turn influence internal control. Internal controls are run to ensure the achievement of operational goals and performance Masli et al. (2010).

Sajad et al. (2008) stated that implementation of accounting information systems caused the improvement of manager's decision-making process with internal controls, the quality of the financial reports and facilitated the company's transaction. Therefore, the adaptation of internal control techniques is a critical management issue that ensures the usefulness of internal controls and the achievement of operational objectives. Zhang (2007), Internal controls aim to ensure the reliability of financial information, the effectiveness, and efficiency of operations and the compliance of laws and regulations. The validity of an internal control system affects the significance of internal controls. Hoitaish \& Bedard (2009) the value of internal control influences operational performance through information reliability operational effectiveness. Computerized internal controls have effects on the value of internal controls and performance of operations. The usage of new information technology means computerized controls should be built into the AIS. In conclusion, organization and businesses need have an adequate security control to improve the security of accounting information system and security technology for organizational achievement. 


\subsection{Accounting Information System and Performance Measures}

Accounting information system implementation and success have been comprehensively researched but the contemporary literature shows slight evidence of the relationship between Accounting Information System (AIS) and performance measures. AIS can positively impact on organizations by the following; better adaptation to a changing environment, better management of arm's length transactions and a high degree of competitiveness. There is also a boost to the dynamic nature $\mathrm{s}$ with a greater flow of information between different staff levels and the possibility of the new business on the network and improved external relationships for the firm, mainly with the foreign customers accessed through firm's web. Elena et al. (2010). With the existence of more intercommunication, there are increased chances for diversification of traditional businesses to improve firm's performance. Ogah (2012) reveals that high level of profitability is not dependent on the use of accounting information. The low explained variability implies that other variables apart from AIS positively impact on the bank's profitability. This is true as the employment of AIS if not supported with necessary and enabling facilities to make it functional becomes monumental, which may affect the bank's operation process.

Thus, the successful integration of AIS will depend on how well other factors are efficiently put in place to facilitate its operation. Similar opinion has been echoed by scholars, for instance, Markus \& Pfeffer (1983) asserted that the successful implementation of accounting systems requires a fit between three factors such as perception of the organization concerning the situation, the accounting system must fit when problems are normally solved and the accounting system must fit with the culture, i.e. the norms and value system that characterize the organization. Grande et al. (2011) argued that IT is readily available and using them gives no competitive advantage for achieving improved results. They argued that many firms have invested in IT but they fail in attaining the established performance goals. This, therefore, implies that AIS can only be used in organizational operations when appropriate factors are put in place and operated harmoniously. Akpan \& Riman (2012) used Return on assets (ROA), Return on equity (ROE) and Non-Performing Loans (NPL) for measures of bank performance. While Poudel \& Hovey (2013) apply a ratio of non-performing loan (NPL) to measures the efficiency of the firm. A study by Razak et al., (2011) were used ROA to determine accounting performance and used Tobin's $\mathrm{Q}$ which is a sign of market performance for measures the firm performance of Malaysian GLCs and in-GLCs. Bhagat and Bolton (2008) were measured operating performance by using Tobin's Q and ROA in their research.

\section{Conclusion}

The study has provided an understanding that accounting information system (AIS) has become a system that that is very important in an organization because it generates important information for the organization for decision making and quality of accounting information. The main goal of accounting information system is to control the business held by the organization to prevent and minimize fraud and errors to achieve the organizational goals and improved performance, and for the system (AIS) to generate the accounting information expected, an internal control is required which is the main ingredient of the system. The study also revealed that the development and application of information technology (IT)makes it possible for companies to support operations with IT systems to improve operating performance, and companies have to adjust their technique and method of internal control in accordance with computerization (AIS) in order to exercise effective control because the adaptation of quality internal control affect operation and the achievement of operations. Also, the implementation of accounting information system could lead to better decision making and effective control system to improve firm performance.

\section{References}


Abu-Musa, A. A. (2010). Investigating Adequacy of Security Controls in Saudi Banking Sector: An Empirical Study. Journal of Accounting, Business \& Management, 17(1),1-41.

Akpan, E. S., \& Riman, H. B. (2012). Does corporate governance affect bank profitability? Evidence from Nigeria. American International Journal of Contemporary Research, 2(7), 1-4.

Bhagat, S., \& Bolton, B. (2008). Corporate governance and firm performance. Journal of Corporate Finance, $14,257-273$.

Collier, P. M. (2015). Accounting for managers: Interpreting accounting information for decision making. John Wiley \& Sons. Fourth Edition, Chichester UK.

Gelinas, U. \& Dull, B. (2012). Accounting information system $.9^{\text {th }}$ edition. USA: South-Western Centage Learning.

Grande, U. E. Estebanez, P. R. \& Colomina, M.C (2011). The impact of accounting information on performance measures: empirical evidence in Spanish SMEs. The International Journal of Digital Accounting Research, (11), 25-43.

Hall, James A. (2011). Accounting information system s.7th edition, Mason -USA: South-Western Centage Learning.

Kieso, E., Weygandt J., \& Terry D. (2011). Intermediate accounting $14^{\text {th }}$ edition, John Wiley 7 sons, Inc. New Jersey USA.

Laudon, K.C \& Laudon, J.P (2012). Essentials of Management Information Systems, 6th in. New Jersey: Prentice Hall.

Markus, M. L., \& Pfeffer, J. (1983). Power and the design and implementation of accounting and control systems. Accounting, Organizations and Society, 8(2), 205-218.

Marshal, B. R \& Paul J.S. (2015). Accounting Information Systems. Thirteen Edition. Pearson Education Limited. 214-234.

McLeod A. and Shell, G.P. (2007). Management information system .10th Edn., Prentice Hall, New Jersey, USA.

O’Brien, James A.\& Maracas, George M. (2010). Introduction to information system $.15^{\text {th }}$ edition. NY: McGrew-Hill Irwin.

Ogah, I.J. (2012). An evaluation of the relevance of accounting system as a management decision tool in Union Bank of Nigeria PLC. Uyo branch of Akwa Ibom Greener. Journal of Business and Management Studies 3(1), 38-45.

Razak, N. H. A., Ahmad, R., \& Joher, H. A. (2011). Do government-linked companies (GLCs) perform better than non-GLCs? Evidence from Malaysian listed companies. Journal of Applied Finance and Banking, 1(1), 213-240.

Romeney, B., \& Steinbart, J. (2013). Accounting information systems. Prentice Hall business publishing (9th Ed), 58-66. Arizona

Romney, B.M. and Steinbart, J.P. (2012). Accounting information system. 12th edn., Pearson Prentice Hall. Edinburgh gate Halow. England.

Romney, M. B., \& Steinbart, P. J. (2015). Accounting Information System Thirteen Edition. Pearson Education Ltd. Edinburgh gate Halow. England.

Sajady, H., Dastgir, M. and Hashemnejad (2008). Evaluation of the effectiveness of accounting information systems. International Journal of Information Science \& Technology, 6(2) ,62-67.

Shah, H., Malik, A., \& Malik, M. S. (2011). Strategic Management Accounting-A Messiah for Management 
Accounting. Australian Journal of Business and Management Research, 1(4), 11-23.

Soudani, S. N. (2012). The usefulness of an accounting information system for effective organizational performance. International Journal of Economics and Finance, 4(5), 136-141.

Stair, R.M, and Reynolds, G.W. (2010). Principles of information system.9th edition. course technology. Boston, Massachussetts, U.S.A.

Susanto, A. (2013). Accounting Information Systems: Development of Risk Control Structure. Prime Edition. First mold. Bandung: Lingga Jaya.

Topash, N.K (2014):: Evaluation of Efficiency of Accounting Information Systems: A Study on Mobile Telecommunication Companies in Bangladesh. Global Disclosure of Economics and Business, 3(1), 40-55.

Wilkinson, J.W., Cerullo, M.J., Raval, V.and Wong-On-Wing, B.(2000).Accounting Information Systems: Essential concepts and Applications. Network: John Wiley and sons.

$\mathrm{Xu}, \mathrm{H}$. , (2003) Critical success factors for accounting information system data quality, dissertation, University of Southern Queensland.

XU, H., (2009): Data quality issues for accounting information system implementation: systems stakeholders, and organizational factors, journal of technology research volume 1, pp, 1-11

Yang, M. H., Lin, W. S., \& Koo, T. L. (2011). The impact of computerized internal controls adaptation on operating performance. African Journal of Business Management, 5(20), 8204.

\section{Copyrights}

Copyright for this article is retained by the author(s), with first publication rights granted to the journal.

This is an open-access article distributed under the terms and conditions of the Creative Commons Attribution license (http://creativecommons.org/licenses/by/4.0/). 